
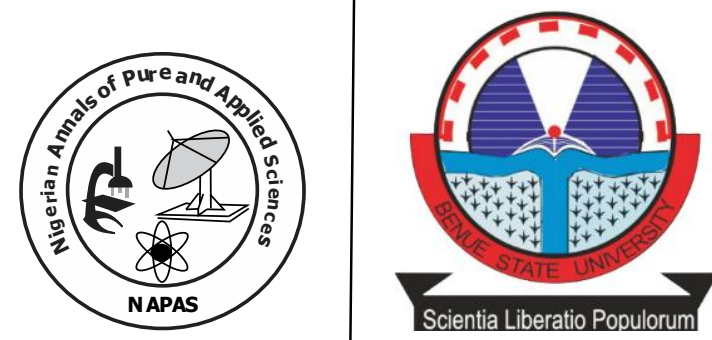

\title{
Model Estimates and In-situ Measurements of the Concentrations of some Gaseous Pollutants in some selected Standard Kitchens in Makurdi-Nigeria
}

\author{
Ichaver, A., Korna, R.T. and Hongor, D.S. \\ Department of Physics, \\ University of Agriculture Makurdi, Nigeria. \\ Corresponding author: ichaveralex@gmail.com
}

doi: https//doi.org/10.46912/napas.184

\begin{abstract}
This work assessed and compared the concentrations of some gaseous pollutants in some selected standard kitchens in Makurdi-Nigeria using in-situ measurements and models estimates. Mean concentrations of $\mathrm{CO}, \mathrm{NO}_{2}$ and $\mathrm{SO}_{2}$ were measured using Crowcon gasman meters in all the selected kitchens. The results obtained show that $\mathrm{CO}$ and $\mathrm{NO}_{2}$ concentrations were observed in all the selected kitchens in concentrations below the permissible limit of $20 \mathrm{ppm}$ and $0.6 \mathrm{ppm}$ respectively set by National Ambient Air Quality Standard and $\mathrm{SO}_{2}$ was not observed. The mean concentrations for model estimates were found to be slightly higher compared to that of in-situ measurement in all the study kitchens for both pollutants, which is an indication of the strength of the model estimate. Pearson product moment correlation coefficient ( $\mathrm{r}$ ) was also computed to be 0.99 and 0.36 for $\mathrm{CO}$ and $\mathrm{NO}_{2}$ respectively. The correlation is very strong and positive for $\mathrm{CO}(\mathrm{r}=0.99)$ and is weak but also positive for $\mathrm{NO}_{2}(\mathrm{r}=0.37)$. This implies that the model estimates used in this work has $99 \%$ validity estimating indoor concentrations of $\mathrm{CO}$ where in-situ measurements are not possible. However, the positive correlation between the in-situ measurements and models estimates indicate that both are positively related.
\end{abstract}

Keywords: Standard kitchen, Gaseous pollutants, Permissible limit, Carbon (II) monoxide, Nitrogen (IV) oxide and Sulfur (IV) oxide. 


\section{Introduction}

A standard kitchen is a room in a structure with number of extractors that is used or designed to be used for preparation or cooking of food and contains one or both of the following:

(i) Cooking appliances or rough in facilities including, but not limited to: ovens, convection ovens, stove, microwave ovens or similar appliances, 240 volt electrical outlets or any gas line. (ii) a sink less than eighteen (18) inches in depth with a waste line drain one and a half $\left(1 \frac{1}{2}\right)$ or greater in diameter and a refrigerator exceeding five (5) cubic feet in capacity space opening with an electrical outlet that may reasonably be used for a refrigeration exceeding five (5) cubic feet in capacity (Jennifer et al. 2014).

On the other hand, an air exchange rate (AER) depicts a measure of the air volume added to or removed from a space (normally a room or house) per hour divided by the volume of the space.

Gas cooking appliances are used in about half of the roughly 12 million housing units in some developed countries (Jenifer et al., 2014). Gas cooking burners emit air pollutants that can affect residential indoor air quality and increase health risks. Emitted pollutants include nitrogen (IV) oxide $\left(\mathrm{NO}_{2}\right)$, carbon (II) oxide (CO), and Sulfur (IV) oxide $\left(\mathrm{SO}_{2}\right)$.Increased indoor $\mathrm{NO}_{2}$ and $\mathrm{CO}$ concentrations from gas cooking appliances have been associated with adverse health effects such as wheezing and decreased respiratory function Jenifer et al.(2014).Many studies have examined gas appliance-related concentrations of $\mathrm{NO}_{2}$ and $\mathrm{CO}$ concentrations in homes (Spengler et al., 1994, Yang et al., 2004, and Fortmann et al., 2001). Measurement-based studies are imperative for understanding the physical properties that govern concentrations and exposures in homes. However, the costs and logistics of large-scale monitoring are barriers to using this method to quantify population-wide impacts.

In developing countries, the problem of indoor air pollution is increasing at an alarming rate. In rural areas of India, the most important indoor air pollutants are combustion products of unprocessed solid biomass fuels used by the poor rural folk for domestic cooking (Aakanksha et al., 2014). Bio fuels undergo incomplete combustion releasing complex mixtures of organic compounds which include $\mathrm{CO}$, contaminants such as sulfur, and trace metals. A negligible amount of $\mathrm{CO}$ is also released during the use of liquid petroleum gas (LPG).

A study conducted by Singer et al. (2012) measured the concentrations of gaseous pollutants from Natural Gas Cooking Burners (NGCBs) in Indian kitchens and reported peak concentrations of $\mathrm{CO}$ and $\mathrm{NO}_{2}$ during cooking that ranged from $30-45$ ppm and $40-150$ ppm respectively based on a single cook top. They suggested that the hazards posed by NGCBs could be mitigated substantially through the use of venting range hoods that captured cooking burners' pollutants as well as pollutants generated from cooking activities.

A study conducted by Aakanksha et al. (2014) in Lucknow North India to assess air quality in kitchens revealed very high concentration of $\mathrm{CO}, \mathrm{CO}_{2}, \mathrm{NO}_{2}$, and $\mathrm{SO}_{2}$ in Indian kitchens. They found out that, for all fuel sources, the concentrations of these pollutants were higher than the World Health Standard. They suggested that more stringent bio monitoring studies and use of high efficiency cooking devices to employ to cut down the emissions of toxic gases during combustion of bio fuels in Indian kitchens.

Observations were made by Mullen et al. (2012) in Northern California. They measured pollutant levels over 6-days period in the 155 homes. They found that among 155 homes, cooking's were done with gas appliances at least once during sampling; the time-integrated measurements had a fitted $\mathrm{NO}_{2}$ of $12 \mathrm{ppm}$ and $15 \mathrm{ppm}$ in kitchens which exceeded NAAQS.

Another study conducted by Jennifer $e t$ al. (2014) in Southern California to assess the concentrations of $\mathrm{CO}$ and $\mathrm{SO}_{2}$ for natural gas cooking burners (NGCBs) observed that the emissions of these pollutants from natural gas burners exceeded ambient air quality standard in the ranges of $55-70 \%$ and $7-8 \%$ respectively in homes during a typical week in winter. They suggested that reducing pollutant exposures from NGCBs should be a public health priority. Their results suggested that regular use of even moderately effective venting range hoods would drastically reduce the percentage of pollutants in homes in which concentrations exceed healthbased standards.

A community survey was conducted by Olufemi et al. (2011) to assess the pattern and determinants of household sources of energy for 
cooking in rural and urban areas in South Western Nigeria. They found out that biomass fuels emit high level of gaseous pollutants and are the major sources of fuel used in the rural kitchens for domestic cooking. Electricity and gas was found to be the major fuel sources in the urban kitchens.

In another study carried out by Olufemi $e t$ al, (2017) in Southern Western Nigeria to assessed indoor air quality and risk factors associated with respiratory conditions, they observed that there is increased risk of respiratory symptoms and poor lung function test in women using firewood, agricultural waste and charcoal when compared with those using non biomass fuels. They asserted that concentration of $\mathrm{NO}_{2}$ was low in all the studied kitchens and other pollutants were above the permissible limit set by World Health Organization (WHO).

Observations were made by Akpofure (2015) in Wary - Nigeria. He assessed indoor air quality in Squatter settlement and found out that measured level of $\mathrm{NO}_{2}, \mathrm{CO}$ and $\mathrm{PM}$ in the entire sample household were above regulatory limit of $0.06 \mathrm{ppm}, 10 \mathrm{ppm}$ and $250 \mu / \mathrm{m}^{3}$ respectively, as set by the World Health Organization.

Observations from available literatures show that few works have been carried out to ascertain the level of pollutants in Nigerian kitchens. In addition, none of these works has been found to be carried out in kitchens in Makurdi metropolis, Nigeria. Yet majority of the people in this area depend on biomass fuel source for cooking.

Makurdi is located in the north central region of Nigeria along Benue River and at the north-east of Benue State. It lies between Latitude $7.74^{\circ} \mathrm{N}$ and Longitude $8.51^{\circ} \mathrm{E}$ with an elevation of $104 \mathrm{~m}$. Majority of the inhabitants of this town are civil servants. The kitchens were randomly selected at location A, B, C, D and E, at each location, a kitchen was selected. Table 1 gives some standard kitchens in Makurdi metropolis. The names of these kitchens are represented with some codes.

\section{Materials and Methods Materials}

Materials used in this work were: thermometer $\left(0-110^{\circ} \mathrm{C}\right)$, wooden stand (measuring $1.0 \mathrm{~m}$ tall) with a flat top made of wood measuring $15.0 \mathrm{~cm} \times 15.0 \mathrm{~cm}$, Crowcon gasman meters AMS9501S (0-200 Version) and stop watch. The choice of these equipment is necessary because they were designed to assess $\mathrm{CO}, \mathrm{NO}_{2}$ and $\mathrm{SO}_{2}$ in part per million even in relatively inaccessible areas.

\section{Method}

At a selected kitchen, the gasman monitors for measuring $\mathrm{CO}, \mathrm{NO}_{2}$ and $\mathrm{SO}_{2}$ were placed on the wooden stand of 1.0 meter tall (which is the average height of standing and sitting human being) which was kept inside the kitchen. The gasman monitors were switched on simultaneously and readings were taken in every 5 minutes for 1 hour per day per study kitchen for six days. The average concentrations of the gaseous pollutants were then computed and recorded. This procedure was repeated in all the kitchens.

The indoor gaseous pollutants from cooking gas burners were measured using gasman monitors and mean concentration of the pollutants obtained using the expression (Eguda, 2006):

$$
C_{a v}=\frac{\sum c_{i}}{n}
$$

where

$C_{a v}$ is the average concentration of pollutants, $C_{i}$ is the pollutant concentration and $\mathrm{n}$ is the number of observations. The daily mean concentrations of gaseous pollutant were also computed using equation 1 .

However, the estimation of indoor and outdoor pollutants was carried out using models adapted from Singer et al. (2012):

$$
\begin{aligned}
& C_{\text {inI } i}=\frac{E(t)}{V}\left[\left(k_{i}+a\right) t+1\right] \\
& \text { and } \\
& C_{\text {in } O} i=a C_{\text {out } i}\left[\left(k_{i}+a\right) t+1\right]
\end{aligned}
$$

The $C_{i n I} i$ is the indoor pollutant concentrations from indoor sources, $C_{\text {in } O} i$ is the indoor pollutant concentrations from outdoor sources, $I$ is the pollutant species $\left(\mathrm{CO}, \mathrm{NO}_{2} \mathrm{SO}_{2}\right)$, $V$ is volume of the kitchen, $E_{\mathrm{i}}$ is the emission rate, $k_{\text {i }}$ first-order deposition rate constant, $a$ is air exchange rate (AER), and $t$ is time.

Equations 2 and 3 were each solved for $C_{\text {inI,i }}$ and $C_{\text {inO,i, }}$ respectively, with any of the parameters held constant. Equation 2 presents the solution for the indoor concentration resulting from gas emission from indoor sources, while equation 3 is the solution for indoor concentration originating from outdoor sources. Combining equations 2 and 3 gives the total pollutant 
concentrations computed as the summed contributions from the two sources. Thus,

$$
C_{\text {in } i=} C_{\text {in I } i}(t)+C_{\text {in } O i}(t)
$$

Because of the closeness of the cooks and the gas cooking burners, the probability of human effects that would exist from gaseous pollutants emissions was computed from the mean concentration values using the relation given by Ediagbonya et al. (2013) as:

Toxicity potential $(\mathrm{TP})=\frac{\text { observed mean conc.of the species }}{\text { Permissable limit set by NAAQS }}$

TP $>1$ is harmful to human.

Using the correlation model, the relationship between measured and modeled pollutant concentrations was computed. Hence

$$
r=\frac{i \sum C_{m e s} C_{e s t}-\sum C_{m e s} C_{e s t}}{\sqrt{i\left[\sum C_{m e s^{2}}-\sum(m e s)^{2}\right]\left[i \sum C_{e s t^{2}}-\sum\left(C_{e s t}\right)^{2}\right]}}
$$

the correlation coefficient, $r$ was computed using the expression adopted from Adikwu et al. (2013):

where $\mathrm{i}$ is the number of pairs of data described by the coefficient, $C_{m e s}$ is the measured pollutant concentrations and $C_{\text {est }}$ is the modeled or estimated pollutant concentrations.

Table 1: Some selected standard kitchen

\begin{tabular}{ccclccc}
\hline Kitchen codes & Volume & Fuel source & Ventilation & Aver temp. & \multicolumn{2}{c}{ No of extractors } \\
\hline BH & 5852 & Gas & Cross & $39^{\circ} \mathrm{C}$ & 1 large \\
TG & 5544 & Gas & One side opened & $40^{\circ} \mathrm{C}$ & 3 small \\
SF & 5742 & Gas & Closed & $45^{\circ} \mathrm{C}$ & 3 small \\
GP & 5236 & Gas & Closed & $41^{\circ} \mathrm{C}$ & 2 small \\
CF & 4992 & Gas & Closed & $39^{\circ} \mathrm{C}$ & 3 small \\
\hline
\end{tabular}

\section{Results and Discussion Results}

The results of the in-situ and modeled mean concentrations of some gaseous pollutants in standard kitchens obtained using equations $2-$ 4 are presented in Table 2. On the other hand Table 3 gives the computed Toxicity potential
(TP) for pollutant types in the kitchens, while Table 4 gives the correlation coefficient between monthly measured $\left(\mathrm{C}_{\mathrm{mes}}\right)$ and estimated $\left(\mathrm{C}_{\text {est }}\right) \mathrm{CO}$ and $\mathrm{NO}_{2}$ concentration in the selected kitchens. In addition, Figure 1 portrays the comparisons of the measured and estimated mean concentrations of the gaseous pollutants in the standard kitchens.

Table 2: Measured and estimated mean concentrations of gaseous pollutants in the selected standard kitchens in Makurdi

\begin{tabular}{|c|c|c|c|c|c|c|c|c|c|}
\hline \multicolumn{2}{|c|}{ Kitchens } & \multicolumn{8}{|c|}{ Concentrations of gaseous pollutant (ppm) } \\
\hline $\mathbf{C O}$ & \multicolumn{3}{|c|}{$\mathrm{NO}_{2}$} & \multicolumn{2}{|c|}{$\mathrm{SO}_{2}$} & \multirow[b]{2}{*}{ Cest } & \multirow[b]{2}{*}{ Cout } & \multirow[b]{2}{*}{$C_{m e s}$} & \multirow[b]{2}{*}{$C_{\text {est }}$} \\
\hline & Cout & $C_{m e s}$ & $C_{\text {est }}$ & Cout & $C_{m e s}$ & & & & \\
\hline $\mathrm{BH}$ & 0.004 & 2.040 & 2.060 & 0.0010 & 0.100 & 1.646 & 0.000 & 0.000 & 0.000 \\
\hline TG & 0.008 & 3.790 & 3.980 & 0.0010 & 0.100 & 0.993 & 0.000 & 0.000 & 0.000 \\
\hline GP & 0.006 & 2.630 & 2.800 & 0.0004 & 0.100 & 1.427 & 0.000 & 0.000 & 0.000 \\
\hline SF & 0.009 & 3.640 & 3.880 & 0.0001 & 0.100 & 1.857 & 0.000 & 0.000 & 0.000 \\
\hline $\mathrm{CR}$ & 0.009 & 5.350 & 5.772 & 0.0001 & 0.100 & 0.211 & 0.000 & 0.000 & 0.000 \\
\hline
\end{tabular}
metropolis

Note: $C_{\text {oul }}=$ measured mean concentration of outdoor gaseous pollutants

$C_{m e s}=$ measured mean concentration of indoor gaseous pollutants

$C_{e s t}=$ estimated mean concentration of indoor gaseous pollutants 
Table 3: Toxicity potential (TP) for pollutant types in the kitchens

\begin{tabular}{llll}
\hline Kitchen type & Pollutant & TP & Effect \\
\hline $\mathbf{B H}$ & $\mathrm{CO}$ & 0.102 & Not harmful \\
& $\mathrm{NO}_{2}$ & 0.025 & Not harmful \\
& $\mathrm{SO}_{2}$ & 0.000 & Not harmful \\
$\mathbf{T G}$ & $\mathrm{CO}$ & 0.190 & Not harmful \\
& $\mathrm{NO}_{2}$ & 0.170 & Not harmful \\
& $\mathrm{SO}_{2}$ & 0.000 & Not harmful \\
$\mathbf{G P}$ & $\mathrm{CO}$ & 0.134 & Not harmful \\
& $\mathrm{NO}_{2}$ & 0.170 & Not harmful \\
& $\mathrm{SO}_{2}$ & 0.000 & Not harmful \\
$\mathbf{S F}$ & $\mathrm{CO}$ & 0.182 & Not harmful \\
& $\mathrm{NO}_{2}$ & 0.170 & Not harmful \\
& $\mathrm{SO}_{2}$ & 0.000 & Not harmful \\
$\mathbf{C R}$ & $\mathrm{CO}$ & 0.268 & Not harmful \\
& $\mathrm{NO}_{2}$ & 0.170 & Not harmful \\
\hline
\end{tabular}

Table 4: The correlation coefficient between monthly measured $\left(\mathrm{C}_{\text {mes }}\right)$ and estimated $\left(\mathrm{C}_{\mathrm{est}}\right) \mathrm{CO}$ and $\mathrm{NO}_{2}$ concentration in the selected kitchens.

\begin{tabular}{cccc}
\hline Pollutant & \multicolumn{2}{l}{ Monthly concentration $(\mathrm{ppm})$} & Correlation coefficient $(\mathrm{r})$ \\
& $\mathrm{C}_{\text {mes }}$ & $\mathrm{C}_{\text {est }}$ & $(\mathrm{r})$ \\
$\mathrm{CO}$ & 17.47 & 18.49 & 0.99 \\
$\mathrm{NO}_{2}$ & 05.00 & 06.14 & 0.37 \\
\hline
\end{tabular}

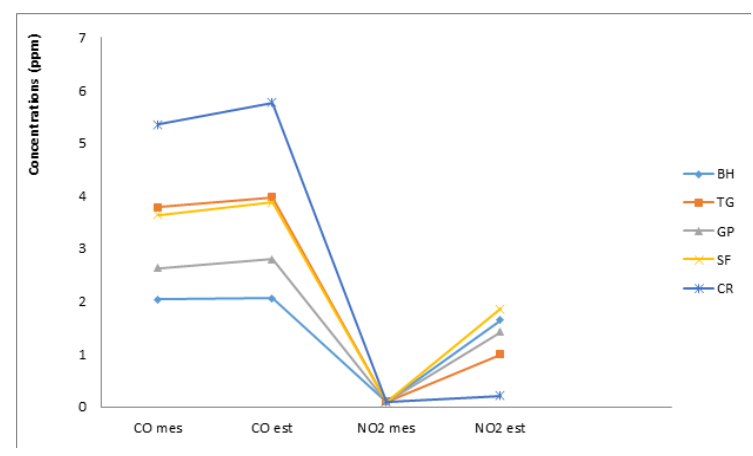

Figure 1: Comparison of measured and estimated mean concentrations of gaseous pollutants in the standard kitchens.

\section{Discussion}

The result in Table 2 which give the mean measured and estimated concentration of some gaseous pollutants from outside $\left(\mathrm{C}_{\text {out }}\right)$ and inside $\left(C_{\text {in }}\right)$ the kitchens indicate a very low concentration of the gaseous pollutants outside the kitchens with the least mean $\mathrm{CO}$ concentration of 0.004 and 0.006 ppm obtained outside BH and GP kitchens respectively. On the other hand, the highest mean $\mathrm{CO}$ concentration of $0.009 \mathrm{ppm}$ observed each from outside CR and SF kitchens. A careful observation of Table 2 and Figure 1 shows that, model estimation yield slightly higher values of mean $\mathrm{CO}$ concentrations as compare to in-situ measurement. This might be as a result of effectiveness of model estimation. A slight positive deviation from $\mathrm{C}_{\text {mes }}$ and $\mathrm{C}_{\text {est }}$ in Table 2 indicates that both in-situ method and model estimation are positively correlated. This was contrary to the findings of Jenifer et al. (2014) who assessed the concentrations of $\mathrm{CO}$ and $\mathrm{SO}_{2}$ for natural gas cooking burners (NGCBs) in Southern California and observed that the emission of these pollutants from natural gas burners exceeded ambient air quality standard in $55-70 \%$ and $7-8 \%$ in homes during a typical week in winter. However, this discrepancy could as well be due to location and infrastructural differences (REFERENCE).

In addition, the results of Table 2 and Figure 1 comparing $\mathrm{C}_{\text {mes }}$ and $\mathrm{C}_{\text {est }}$ concentrations of $\mathrm{NO}_{2}$ showed a wide difference of $0.8-0.9 \mathrm{ppm}$. The results also showed that the highest mean measured and estimated $\mathrm{CO}$ concentration of 5.35 and $5.77 \mathrm{ppm}$ respectively obtained in CR kitchen is below NAAQS of $20 \mathrm{ppm}$. This was contrary to 
a study conducted by Singer et al. (2012), who measured the concentrations of gaseous pollutants from NGCBs in Indian kitchens and reported peak $\mathrm{CO}$ and $\mathrm{NO}_{2}$ during cooking that ranged from 3045 and 40 - 150 ppm which is above WHO standard. This could also be due to location differences (REFERENCE).

Table 3 gives the result of T.P. obtained for all the pollutants in the sampled kitchens. It could be observed that the pollutants are not harmful in the kitchens since T.P for the pollutants in all the selected kitchens is less than one. This confirms the fact that the concentrations of these gaseous pollutants are below the NAAQS.

The result in Table 4 gives the correlation coefficient ( $r$ ) for measured and estimated model for gaseous pollutants. The correlation is very strong for $\mathrm{CO}$ with $\mathrm{r}=0.99$ and is weak for $\mathrm{NO}_{2}$ with $\mathrm{r}=0.37$. This implies that the model used in this work has $99 \%$ validity estimating indoor concentrations of $\mathrm{CO}$ where in-situ measurements are not possible.

\section{Conclusion}

The result from this study show that there exists a low concentration of gaseous pollutant $\left(\mathrm{CO}\right.$ and $\left.\mathrm{NO}_{2}\right)$ in Makurdi standard kitchens and that $\mathrm{SO}_{2}$ was not observed in all of the selected kitchens. The findings indicate that the level of pollutant concentrations is not harmful in the kitchens as T.P. for all the pollutant is less than one. The result for both model estimate and in-situ measurement for assessing gaseous pollutant concentrations yields similar results. This study therefore concludes that any of the two methods can be adopted for the assessment of indoor gaseous pollutant.

\section{Recommendations}

This study therefore, recommends more stringent bio monitoring studies and use of high efficiency cooking devices to cut down the emission of gaseous pollutants during combustion of bio fuels in Makurdi kitchens. The study further recommends that awareness should be created to kitchen owners on the need to assess pollutants concentration in their kitchens so that they will allow more researchers and provide factual information of their kitchens.

As a result of financial constraint, this work was confined to Benue State. It is therefore recommend that other scholars wishing to carry a similar research should extend their studies to other States in Nigeria. It is also recommend that others should carry out the assessment to include other types of pollutant for both kitchens and living rooms.

\section{Acknowledgment}

We acknowledge Benue State Environmental Protection Agency for providing us with their equipment.

\section{References}

Aakanksha, R.; Katiyar, S. and Rastogi, S.K. (2014). Study of Indoor Air Quality of Kitchens of rural Areas in Lucknow. Curr World Environ. 9: 2.

Adikwu, O; Aduloju, M.O; and Emaikwu S.O. (2013). Measure of Association. Research Methods and Statistics in Education. A text book published by Lanrad print, 1:94 - 97.

Akpofure, R. R. (2015). Assessment of Indoor Air Qquality in Selected Households in Squatter Warri Nigeria. Advance in life science. Journal of scientific and academic publishing. 5(1): 1-11.

Ediagbonya, T.F.; Ukpebor, E.; Okiemien, F. and Ogunbowa, G. (2013). Spatio-temporal Distribution of Inhalable and Respirable PM in Rural Atmosphere of Nigeria. Environmental Skeptics and Critics, 2 (1): 20-29.

Eguda, S.O. (2006). Regression and Correlation Analysis. A Text Book on Statistical Methods. Published by Asofad Printing Limited, $2^{\text {nd }}$ Edition 9: 75-78.

Fortmann, R.; Kariher, P. and Clayton, R. (2001). Indoor Air Quality: Residential Cooking Exposures. Final Report. Sacramento, CA: California Air Resources Board.

Jennifer, M.L.; Neil, E.K.; Agnes, B. L, and Brett, C. S. (2014). Pollutant Exposures from Natural Gas Cooking Burners: A Simulation - Based Assessment for Southern California. Atmos 26A(11): 2125-2134.

Mullen, N. A.; Li, J. and Singer, B. C. (2012). Impact of Natural Gas Appliances on Pollutant Levels in California homes. Lawrence Berkeley National Laboratory (LBNL) 5970e.

Olufemi, O.D.; Ololade, O.O.; Ebenezer, K.A.; Tolutope, F.K. and Ayodele, I.O. (2011). A community Survey of the Pattern and Determinants of Household Sources of Energy for Cooking in Rural and Urban 
South Western Nigeria. The Pan African Medical Journal 12(2): doi:10.11604/pamj.2012.12.2.1436.

Olufemi, O. D.; Ololade, O.O.; Ebenezer, K. A.; Tolutope, F. K. and Ayodele, I.O. (2017). Indoor Air Quality and Risk Factors Associated with Respiratory Conditions in Nigeria. African Medical Journal. 28

Singer, B.C.; Delp, W.W.; Apte, M.G. and Price, P.N. (2012). Performance of Installed
Cooking Ehaust Devices. Indoor Air 22:224-234.

Spengler, J.; Schwab, M.; Ryan, P.B.; Colome, S.; Wilson, A.L.; and Billick, I. (1994). Personal Exposure to Nitrogen dioxide in the Los Angeles Basin. J Air Waste Manag Assoc 9- 47.

Yang, W.; Lee, K. and Chung, M. (2004).

Characterization of Indoor Air Quality using Multiple Measurements of $\mathrm{NO}_{2}$. Indoor Air 14:105-111. 